\section{Effect of Fluidized Bed Stirring on Drying Process of Adhesive Particles}

\author{
P. Hoffman, * M. Pěnička, and I. Fořt \\ Czech Technical University in Prague, \\ Department of Process Engineering, \\ Technická 4, 16607 Prague, Czech Republic
}

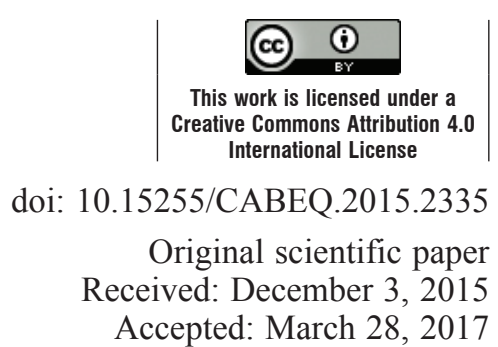

This paper presents an attempt to optimize fluidized bed drying of wet and adhesive particles (with an initial diameter of about $580 \mathrm{~mm}$ ) with the use of stirring, and discusses the influence of stirring on the total drying time. The goal was to demonstrate the positive effect of stirring a fluidized bed to the drying time, to find the optimal parameters (stirrer design, speed, and size). Experiments were conducted on a drying chamber in batch operation. The objective was to evaluate the effect of stirring on the total drying time. The drying chambers were $85 \mathrm{~mm}, 100 \mathrm{~mm}$, and $140 \mathrm{~mm}$ in diameter. An optimal stirrer shape and speed were specified. Our arrangement of the fluidized bed resulted in a decrease in drying time by up to $40 \%$.

Key words:

fluid drying, stirring, mechanical disruption, sticky particles

\section{Introduction}

This paper deals with a search for a way to decrease a fluidized bed drying time of particles in batch mode. Drying is an extremely energy-demanding process, and so it is important - especially now that energy prices are at high levels - to find ways to achieve energy savings. Fluidized-bed drying is a drying process in which intensive heat and mass transfer occurs between particles that are present in a fluid state, and the air flowing through the bed. The drying method is very widely used in various branches of industry ${ }^{1,2}$.

However, when sticky particles are being dried, there are problems with the formation of the fluidized bed. The surface tension of the liquid that covers the dried particles at the start of the drying process produces strong stickiness between the particles, and between the particles and the walls of the drying chamber. Instead of flowing uniformly through the layer of wet particles, the drying air flows in several channels. As a result, the drying time is rather long and there is high energy consumption.

A solution may be found in drying with a fluidized bed layer that is stirred ${ }^{3-6,21-29}$, in which the particle clusters are continuously disintegrated and the particles adhering to the walls of the drying chamber are swept off by the stirring process (see Table 1).

The aim of this work was to reduce the drying time and improve the drying process of the regener-

${ }^{*}$ Corresponding author: email: pavel.hoffman@fs.cvut.cz ated ion exchanger particles, i.e. to shorten the process and at the same time improve the homogeneity of the moisture of the particles.

\section{Dried material}

The goal was to dry the very adhesive spherical particles of an ion exchanger. Ion exchangers are mostly synthetic high-molecular-weight organic compounds, largely based on styrene, polyacrylate, phenol formaldehyde resins, etc. ${ }^{7,8}$ The Marathon-A cation exchanger, consisting of spherical particles $450-580 \mu \mathrm{m}$ in diameter ${ }^{9}$, was selected as the model material. The maximum permitted temperature is $120^{\circ} \mathrm{C}$, in order to avoid thermal stress resulting in structural degradation of the particles ${ }^{10}$. The dry particles have density $1440 \mathrm{~kg} \mathrm{~m}^{-3}$.

The particles are very sticky, due to the surface tension of the water that covers them (Fig. 1). The initial moisture of the particles was about $65-68 \%$. By centrifuging, it was possible to decrease the moisture only down to $52 \%$, but a centrifuge is rather expensive equipment.

\section{Experimental dryer}

An experimental dryer for fluidized-bed drying with a stirred layer and various fluid chamber diameters was designed to evaluate the development of the drying process of adhesive particles. The layout of the experimental equipment is shown in Fig. 2. Pressurized air at a known temperature and humidi- 


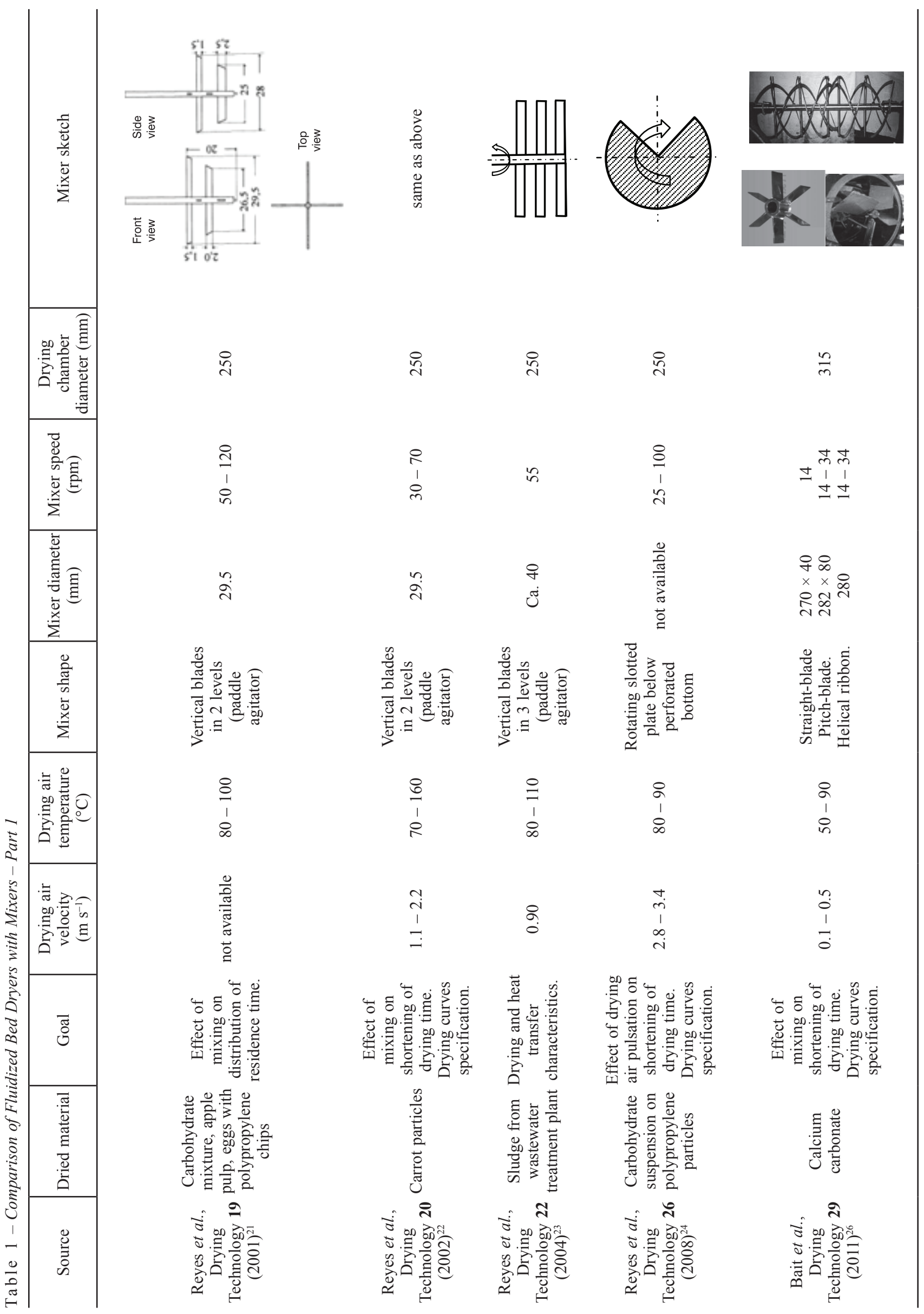




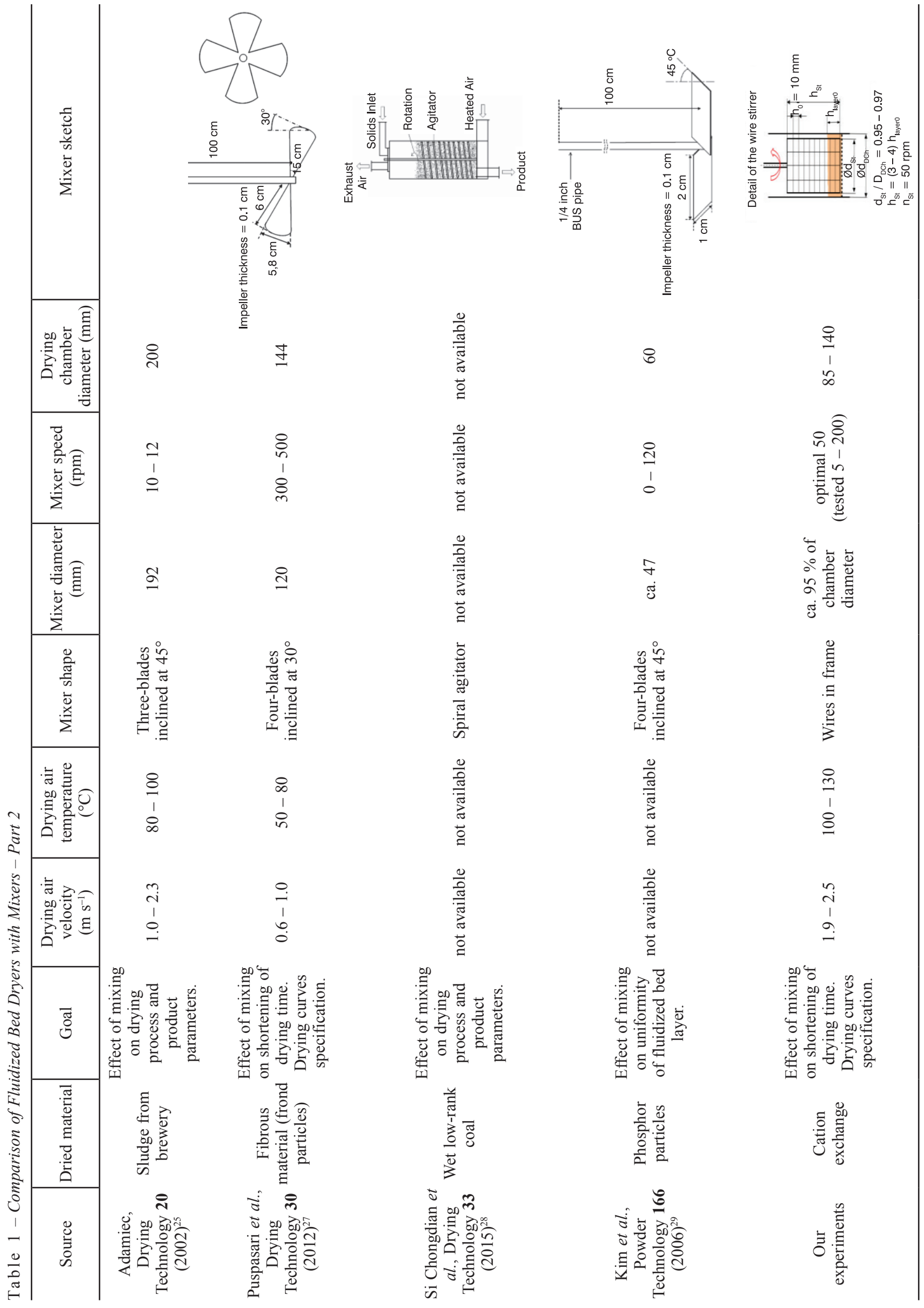




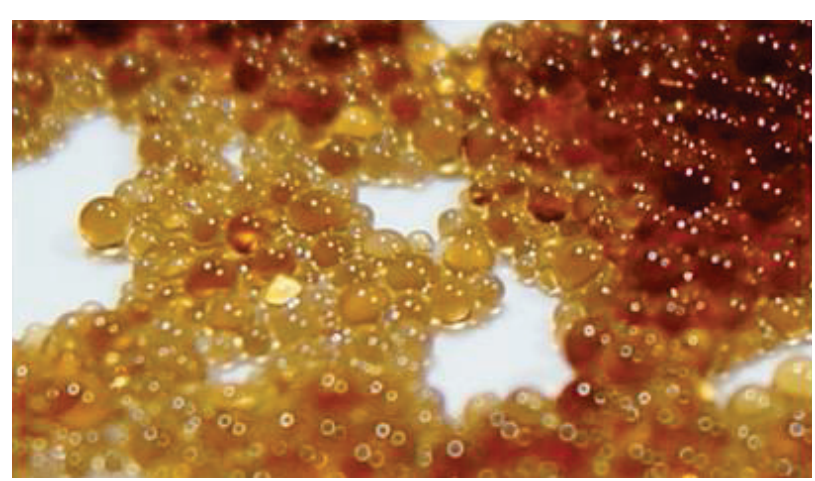

Fig. 1 - Wet particles of the ion exchanger before drying

ty is fed in from the main air distribution line (Fig. 2 , Item 1). The air flow is controlled by the pressure control valve (Fig. 2, Item 2), and is measured using a rotameter (Fig. 2, Item 3 ). The drying air velocity was usually $2.1 \mathrm{~m} \mathrm{~s}^{-1}$, but it was tested in the range from 1.9 to $2.5 \mathrm{~m} \mathrm{~s}^{-1}$. The velocity was sufficient for the proper process of fluidization, and the drying air source and heater were able to prepare the drying air with the necessary flow rate and temperature for dryers with the largest diameter. Downstream from the flowmeter, the air is heated by a heating device with resistance wires, and the output of the unit is controlled manually by changing the voltage, using a transformer (Fig. 2, Item 4).

The temperature of the heated air is measured in the upstream of the fluid chamber, using a contact thermometer with accuracy of $\pm 0.1^{\circ} \mathrm{C}$. We tested drying air temperatures from 100 to $130{ }^{\circ} \mathrm{C}$. The fluidized bed chamber (Fig. 2, Item 5) consists of a duct made of a galvanized zinc sheet, which is thermally isolated. This main part is $1 \mathrm{~m}$ in length, and then the diameter is expanded from $85 \mathrm{~mm}, 100$ $\mathrm{mm}, 125 \mathrm{~mm}$ or $140 \mathrm{~mm}$ to $250 \mathrm{~mm}$. A sensor for

Experimental equipment layout

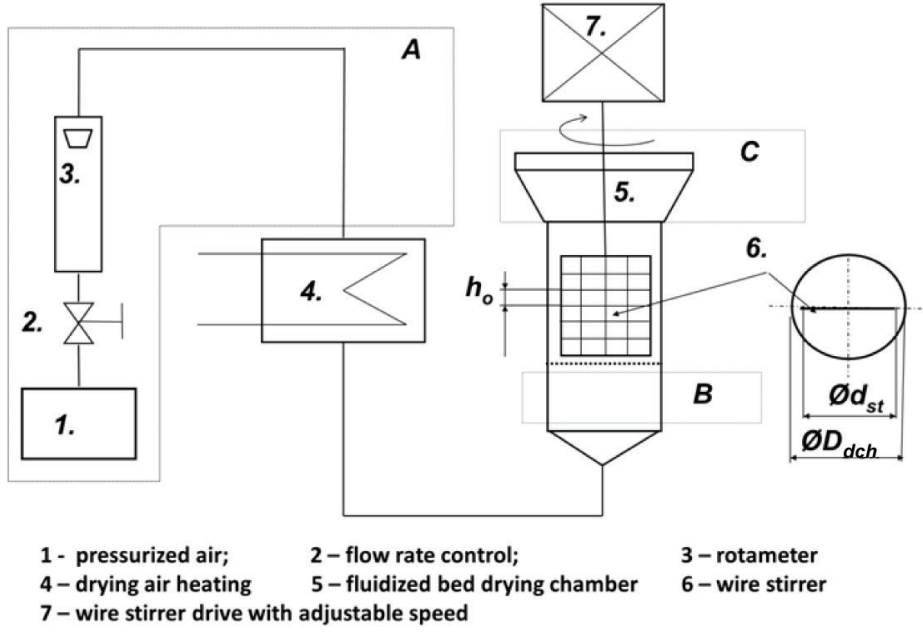

Fig. 2 - Sketch of the experimental dryer $(A, B, C=$ drying air states - see Fig. 4) measuring the humidity of the drying air (accuracy $\pm 0.1 \%$ ) and the temperature of the drying air (accuracy $\pm 0.1 \%$ ) after passing the fluidized bed layer was positioned at a constant height of $300 \mathrm{~mm}$ above the fluidized-bed chamber grid. This sensor is designed to determine the properties of the drying air at the output (part $\mathrm{C}$ in Fig. 4). An adjustable-speed stirrer unit is positioned above the chamber (Fig. 3, Item 7).

A schematic drawing of the wire stirrer is shown in Item 6 of Fig. 2, and its dimensions are indicated in Fig. 3. Fluidized-bed chambers with four basic diameters $\left(D_{\text {dch }}=85 \mathrm{~mm}, 100 \mathrm{~mm}, 125 \mathrm{~mm}\right.$, and $140 \mathrm{~mm}$ ) were designed to enable the development of the model drying process to be precisely monitored.

Firstly, it was necessary to develop an optimal design of the stirrer. Classic stirrers with blades were not efficient, as their mixing effect was insufficient (sticky content of wet particles rotated together with the stirrer like one piece). The main requirement for the proposed stirrer was that it should be able to disrupt existing or forming clumps of sticky dried ion exchanger particles, and to wipe stuck particles off the wall of the dryer. The second goal was to minimize the area of the adhesive layer of sticky particles while minimizing the degradation of the particles. There must be no negative influence of the stirrer in the first and second period of the fluidized drying. The stirrer must not interfere with the fluidized bed, must not prevent an ideal contact between the particulate and the drying air, and must not have an adverse effect on heat transfer and mass transfer.

Further experiments were conducted with various sizes and shapes of the mesh of the mixer. We tested the mesh with following holes: squares
Detail of the wire stirrer

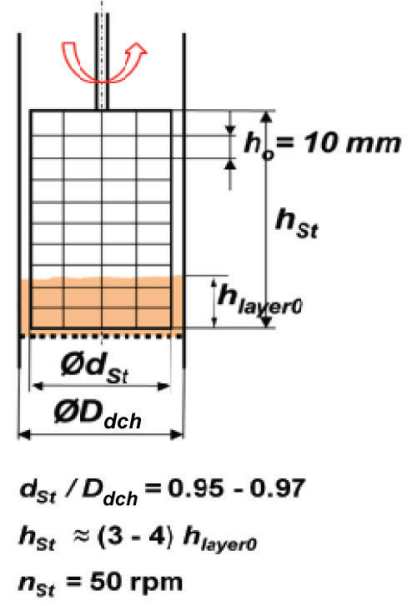

Fig. 3 - Sketch of the wire stirrer 


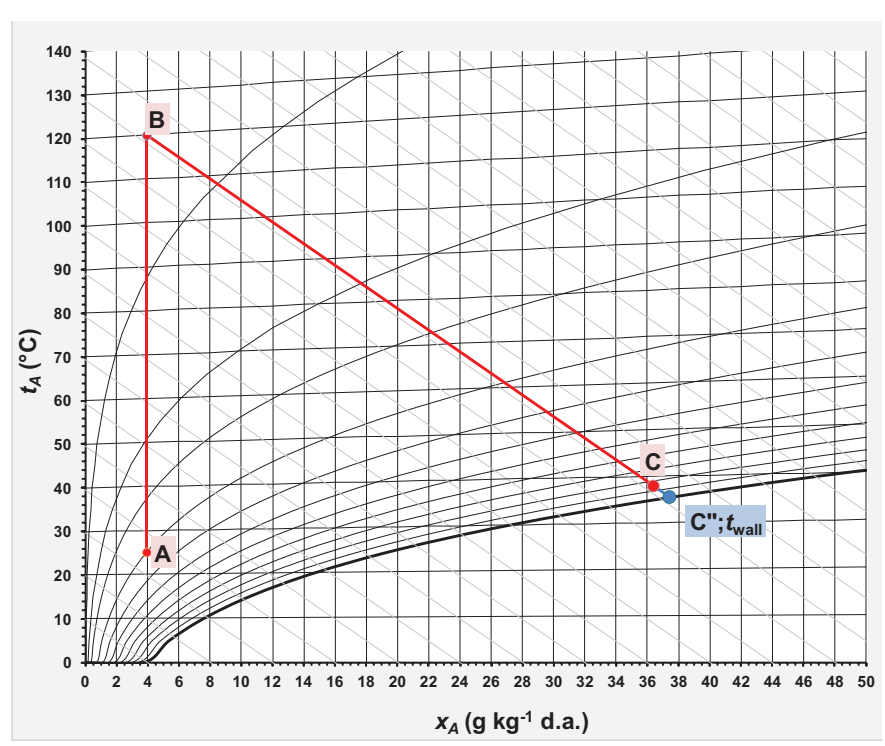

Fig. 4 - Drying air parameters in the $h-X$ diagram of wet air for the adiabatic drying process; $A-B$ drying air heating; $B-C$ particle drying

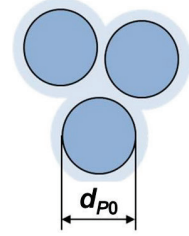

point 0

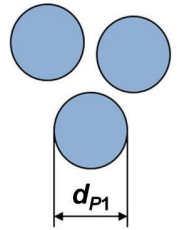

point 1

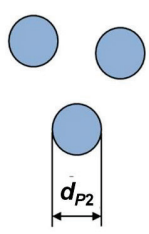

point 2

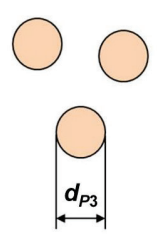

point 3
Fig. 5 - Change in particle diameter during the drying process

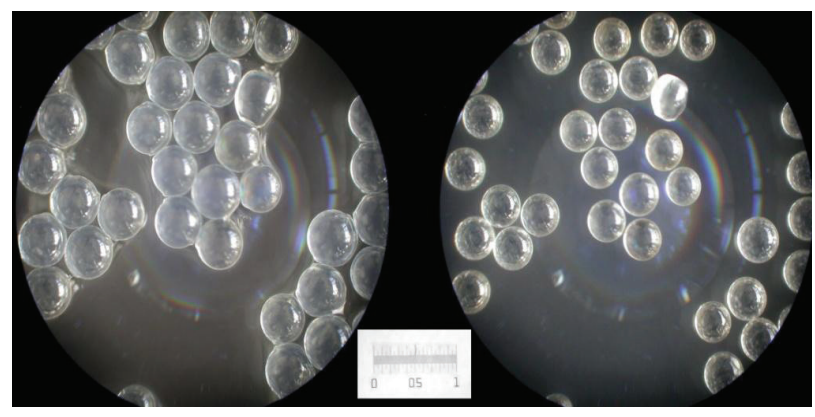

Fig. 6 - Ion exchanger particles during and after drying

$2.5 \times 2.5 \mathrm{~mm}, 10 \times 10 \mathrm{~mm}$ and $25 \times 25 \mathrm{~mm}$, and rectangles $25 \times 2.5 \mathrm{~mm}$ and $25 \times 10 \mathrm{~mm}$, in vertical or horizontal position. The experiments show clearly that, for the small mesh size, the stirrer does not sufficiently disrupt clusters of wet particles, and the cluster of the ion exchanger in the fluid-bed chamber dryer rotates simultaneously with the stirrer. When the mesh size was large, large clusters of particles were disrupted regularly, but small clumps were not. The orientation and the shape of the holes in the stirrer had no significant effect on the disintegration of the clusters. The optimum mesh size for these particles was found to be $h_{0}=10 \times 10 \mathrm{~mm}$ (see Fig. 3).

On the basis of a series of experiments, it was shown that the most suitable stirrer was that presented in Fig. 3. This stirrer is made of stainless steel wire, having a diameter of 0.4 to $0.6 \mathrm{~mm}$. It is designed for a centric arrangement, and the ratio of its diameter to the diameter of the fluidizing chamber $d / D_{d c h}$ is 0.95 to 0.97 . The height of the stirrer $h_{s t}$ is $2.8-5$ times greater than the resting height of the layer of material. We tested a wide range of stirrer speeds from 5 to $200 \mathrm{~min}^{-1}$. The expected optimal speed is approx. $50 \mathrm{~min}^{-1}$. As follows from Table 1 , similar speeds were used by other authors. At this speed, the peripheral speed of the blade tip is in the range from 0.225 to $0.26 \mathrm{~m} \mathrm{~s}^{-1}$.

\section{Results of the experiments}

The height of the layer $h_{\text {layer } 0}$ of wet dried particles in all the experiments was about $50 \mathrm{~mm}$ (see Fig. 2). Preparation of the layer of the dried material was the same for both unmixed and mixed layers. In the dryer, the wet particles were filled with the needed amount. The load of wet particles depended on the chamber diameter, and was about $0.35 \mathrm{~kg}$ for diameter $85 \mathrm{~mm}$, and $0.90 \mathrm{~kg}$ for diameter $140 \mathrm{~mm}$. At time 0 , the drying air began to flow into the dried material. For unmixed layer, there was no mixer; for the mixed layer the mixer started to rotate at the same moment. Fig. 4 shows typical parameters of the drying air. The states of the fresh drying air A, the air after heating B (inlet to the drying chamber), and at the outlet from the drying chamber $\mathrm{C}$, are also shown in Fig. 2.

\section{Change in the diameter of the particles}

Samples were taken from the dryer every 5 minutes to determine particle moisture, and their diameters were determined under microscope. Figs. 5 and 6 show examples of how the diameters of dried particles changed during the drying process. Firstly, the particles are covered with a thin layer of water, which is separated during the $1^{\text {st }}$ drying period $(0-$ $1)$. During this time, the diameter of the particles is constant (see Fig. 7). During period $(0-1)$, their moisture decreases from approx. $65-68 \%$ to about $45 \%$. When the free water is evaporated, the diameter starts to decrease from about $0.58 \mathrm{~mm}$ to about $0.46 \mathrm{~mm}$. During period $(1-2)$, their moisture decreases from about $45 \%$ to approx. $12-15 \%$. In further drying $(2-3)$, and with a corresponding reduction in moisture, the diameter of the particle does not change (see Fig. 7). 


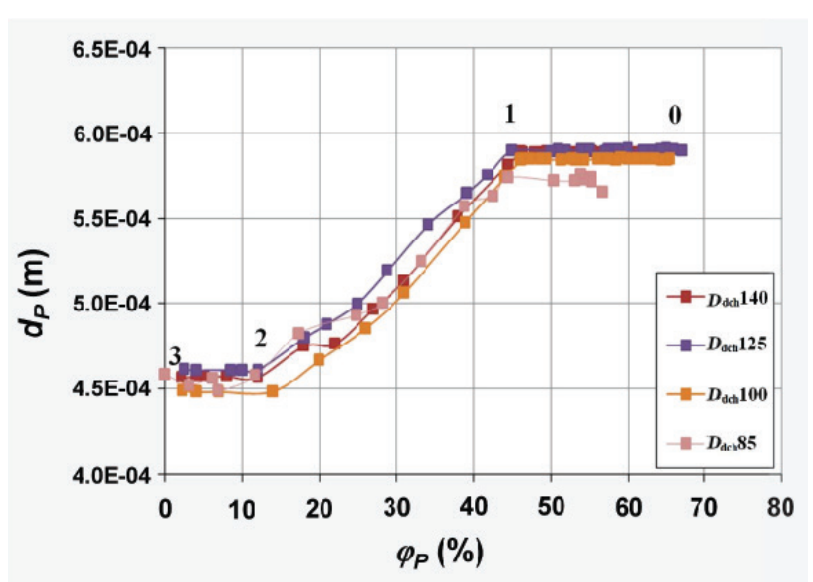

Fig. 7 -Dependence of the change in particle diameter on the relative moisture of the particles
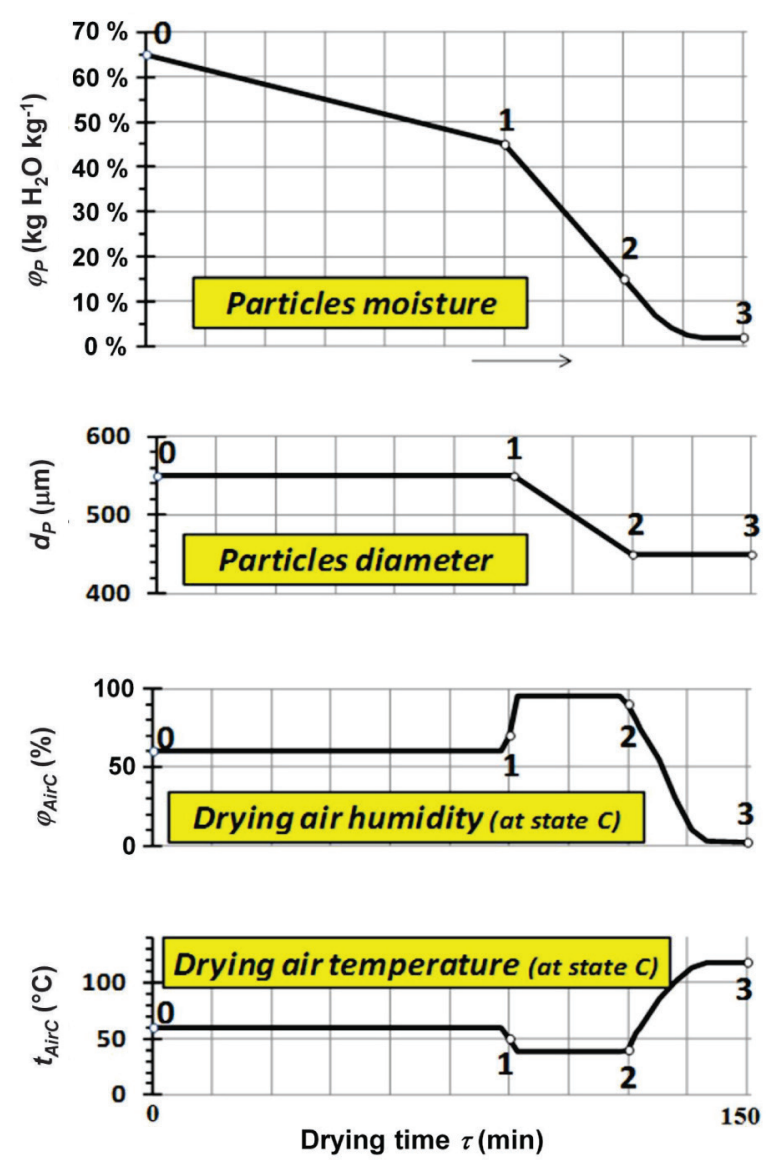

Fig. 8 - Time dependence parameters of particles and drying air throughout the drying process (point $C-$ see Figs. 2 and 4)

Fig. 7 compares the changes in diameter of the particles depending on their relative moisture. These changes were measured in experiments with columns of various diameters. Fig. 7 illustrates that the diameter of the column has virtually no effect on the dependency of the change in the diameter of a particle on its moisture content during the drying process. Based on this finding, we are justified in assuming that the experimental results can be applied to devices operating in industry for drying of these and similar particles.

\section{Typical parameters of the drying process}

Typical parameters of the drying process that were measured in the course of numerous experiments are shown in Fig. 8. The figure shows that there are typical changes in some important measured parameters during the three periods of drying.

In the first drying period $(0-1)$, the particles are very wet and sticky. For this reason, the drying rate is low. When their moisture reaches about 45 $\%$, the dried particles are no longer sticky, and they fluidize with no problem. In this period $(1-2)$, the drying rate is high (their moisture decreases more rapidly - see Figs. 8 and 10).

\section{Determining the porosity of a layer}

The initial conditions for the drying process of particles of the regenerated ion exchanger were identical for all tested sizes of the fluid drying chambers. There was a constant drying air velocity

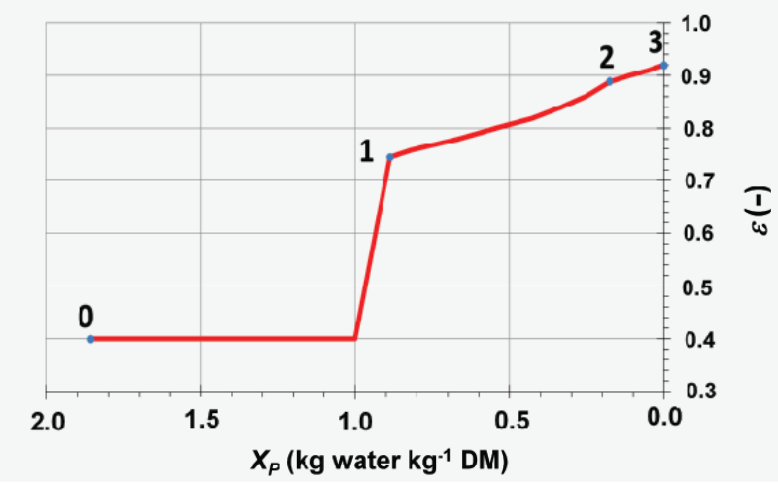

Fig. 9 - Fluid layer porosity $\varepsilon$ (-) vs. moisture content of the particles $X_{p}\left(\mathrm{~kg}\right.$ water $\left.\mathrm{kg}^{-1} \mathrm{DM}\right)$

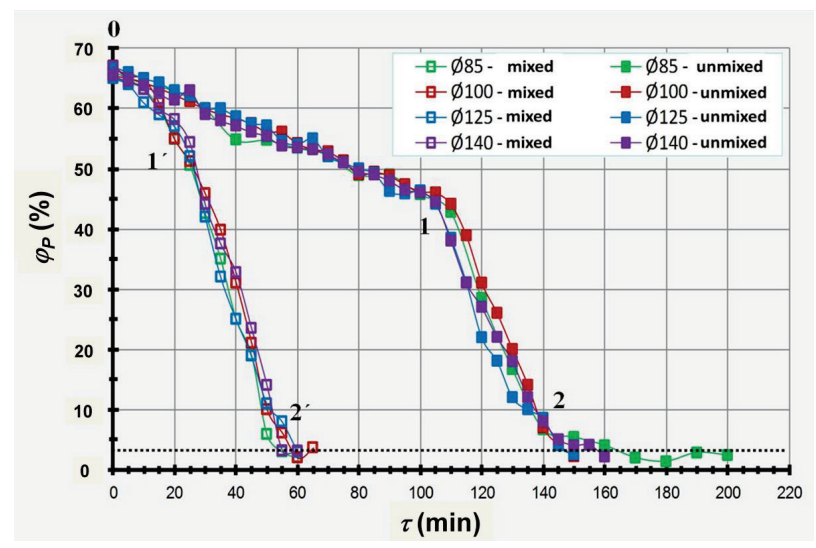

Fig. 10 - Resulting drying curves for mixed and unmixed fluid beds (fluidized-bed dryer chamber diameters $85 \mathrm{~mm}$; 100 $\mathrm{mm} ; 125 \mathrm{~mm}$, and $140 \mathrm{~mm}$ ); Dotted line = prescribed final moisture of the particles 
$u_{A}$ and temperature $t_{A 1}$ in all sizes of the tested columns. The Reynolds number was determined from the known drying air velocity $u_{A_{-} B}$, according to the equation

$$
\operatorname{Re}=\frac{u_{A_{-} B} \cdot d_{p} \cdot \rho_{A}}{\mu_{A}}
$$

where $\mu_{A}$ is dynamic viscosity and $\rho_{A}$ is the density of the drying air. These values are determined according to ${ }^{11} . d_{p}$ is the mean value of the particle diameter in the studied period. The relationship between porosity $e$ and drying air velocity $u_{A B}$, or between porosity and the Reynolds number $R e$, is expressed ${ }^{12}$ by an equation valid for fine particles:

$$
R e=\frac{A r \cdot \varepsilon^{4.75}}{18+0.6 \sqrt{A r \varepsilon^{4.75}}}
$$

The Archimedes criterion $A r$ is determined according to the equation ${ }^{13}$

$$
A r=\frac{d_{p}^{3} \cdot\left(\rho_{S W}-\rho_{A}\right) \cdot \rho_{A} \cdot g}{\mu_{A}^{2}}
$$

where $g$ is the acceleration of gravity, $\rho_{A}$ is the density, and $\mu_{A}$ is the dynamic viscosity of the drying air, determined according to ${ }^{14,15}$. The density of the wet particles $\rho_{S W}$ for the given drying period $(0-1$, $1-2$ or $2-3$ ) is determined using the equation

$$
\rho_{S W}=\rho_{S} \cdot\left(1+\frac{m_{W}}{m_{S}}\right)
$$

where $\rho_{S}$ represents the density of the dried material, $m_{s}$ is the mass of the dry matter of the measured sample, and $m_{w}$ is the mass of the liquid component of the corresponding moisture of the measured material at a given point in the studied process.

\section{Determining the drying rate}

The drying rate is thus determined for the given interval according to the equation ${ }^{16,17}$

$$
-\frac{m_{S}}{A_{S}} \cdot \frac{\Delta X_{W}}{\Delta \tau}=N_{W}
$$

where $\Delta X_{W}$ is the difference in material moisture content between the initial point and the final point of the studied interval, and $\Delta t$ represents the drying time in the given period. The total surface of all particles in the layer was determined according to the formula

$$
A_{S}=V_{P} a_{s},
$$

where the total particles volume $V_{P}$ is calculated from the formula

$$
V_{p}=\frac{m_{S}}{\rho_{S W}}
$$

where $m_{s}$ is the mass of the dry matter of the measured sample, and $\rho_{\text {sw }}$ is the density of the wet particles for the given drying period $(0-1,1-2$ or 2 $-3)$. The specific surface area of particles layer $a_{s}$ is determined according to the formula valid for monodisperse systems of spherical particles ${ }^{18}$

$$
a_{S}=\frac{6 \cdot(1-\varepsilon)}{d_{p}}
$$

where $\varepsilon$ is the porosity in the studied period. The dependence of the porosity for these three investigated periods of drying is shown in Fig. 9.

\section{Comparison of results for drying wet sticky particles with a mixed layer and an unmixed layer}

Fig. 10 compares the results of experiments for drying chamber diameters of $85 \mathrm{~mm}, 100 \mathrm{~mm}, 125$ $\mathrm{mm}$, and $140 \mathrm{~mm}$ for a mixed layer and an unmixed layer.

It follows from the data that the effect of layer mixing does not depend on the diameter of the drying chamber. The effect of layer mixing is very high in the period $0-1$. The drying rate is much higher, and therefore the drying time is shortened to $25 \%$. In the period $1-2$ (the region of particle fluidization), the mixing effect is very low. This is due to the high turbulence in the fluidized bed, which is practically unaffected by the stirring.

A comparison of these curves shows clearly that there is a positive effect of the stirrer on the adhesive layer, and there is a significant decrease in the drying time. Simultaneously, the stirrer causes the particles to move in a fluid state at about 50-55 $\%$ relative moisture, instead of the original value of $45 \%$ relative moisture. The required final relative moisture, depending on the drying air parameters, was usually about $3 \%$. The moisture was set from a technological point of view. During some experiments, we reached the final relative moisture of less than $1 \%$.

The existence of the stirrer has a positive effect on the first period of fluid drying $(0-1)$, because it shifts wet particles adhering to the walls back into the fluidized bed, where the transfer phenomena are intensive. The adhesive layer of particles is disturbed, causing a more uniform flow of drying air through the layer. The result is a substantial reduction in drying time in the entire drying period. Similar experiments were also conducted at various drying air temperatures. The results were as estimated, i.e., the higher the temperature the shorter the drying time, but problems with the layer stickiness were the same. Table 1 presents important parameters of other authors' experiments with mixed fluidized-bed driers. Stirrers used by cited authors 


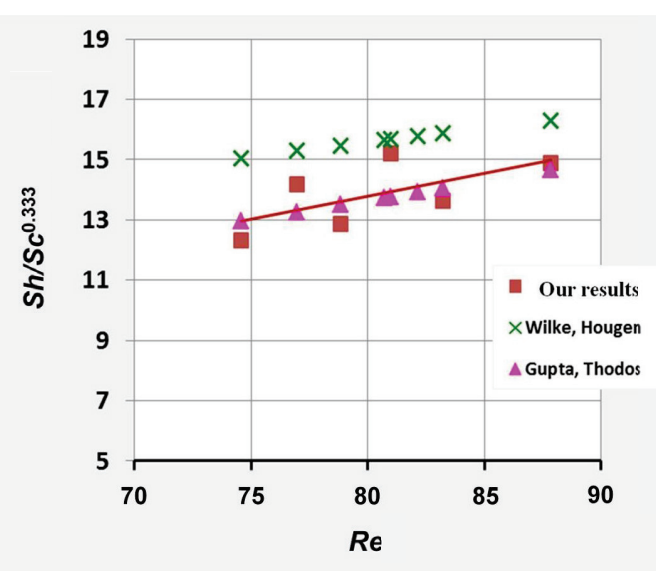

Fig. 11 - Comparison of our results with the experimental results of other authors ${ }^{16,17,19}$

had blades but our stirrer had a quite different design.

It follows from our experiments and their results that, e.g., for the drying air temperature of $120^{\circ} \mathrm{C}$, the drying rate in the first period $(0-1)$ of the porous stationary layer was $8.58 \cdot 10^{-5} \mathrm{~kg} \mathrm{~m}^{-2} \mathrm{~s}^{-1} \pm 5 \%$, and after the stirrer had been introduced, the drying rate increased to $2.81 \cdot 10^{-4} \mathrm{~kg} \mathrm{~m}^{-2} \mathrm{~s}^{-1} \pm 16 \%$, which represents an increase of $220 \%$. In this period, no fluidization was observed as the particles were very sticky. In point 1 , the particles were not sticky and began to fluidize.

In the second $(1-2)$ and third period $(2-3)$ of fluidized-bed drying (the character of the layer in these 2 periods was bubbling bed), the stirrer did not disturb the fluidized bed layer that had formed. It intensified the process to some extent, and the adhered wet particles were swept off the walls of the drying chamber into the fluidized bed. This resulted in a small increase in the drying rate in the second period of fluidized-bed drying, from $2.29 \cdot 10^{-4}$ $\mathrm{kg} \mathrm{m}^{-2} \mathrm{~s}^{-1} \pm 12 \%$ to $2.84 \cdot 10^{-4} \mathrm{~kg} \mathrm{~m}^{-2} \mathrm{~s}^{-1} \pm 17 \%$, i.e., it corresponds to an increase of $17 \%$.

Fig. 11 compares the criteria equation determined from the results of our experiments with the experimental results of Gupta, Todos ${ }^{19}$ and Wilke, Hougen $^{20}$. Each point represents the mean value from a number of measurements. It follows from the comparison that the Sherwood numbers specified according to our experiments are similar to those mentioned here. However, these experiments ${ }^{13,19,20}$ were performed under different conditions from ours (drying air velocity, temperature, dried particles).

The criteria equation derived from our experiments, valid for the mixed layer, is

$$
S h=\frac{\beta \cdot d_{p}}{D_{a, b}}=1.01 \cdot R e^{0,60} \cdot S c^{1 / 3}
$$

where $S h$ is the Sherwood number and $S c=v / D_{a, b}$ is the Schmidt number. This criteria equation gives results similar to those for criteria equations ${ }^{13,19,20}$ (see Table 2). Although we derived it under quite different conditions (dried material and especially different stirrer shape), our relation (9) can also be used in practice for designing similar dryers.

\section{Conclusion}

It has been demonstrated that, for such sticky material, the stirrer made from a wire mesh is better than a stirrer with blades.

It has been demonstrated that our designed stirrer had a positive effect on the wet and sticky layer of dried particles during the first period $(0-1)$ of the drying process in the fluidized-bed layer. The stirrer regularly disturbed the stationary sticky less porous layer that had formed, and thus intensified the rate of the heat and mass transfer. The total drying time to reach the required moisture content of the material was found to be 100 minutes, which corresponds to a $63 \%$ shorter drying time than for the case with no stirrer. The effect of the stirrer in the second $(1-2)$ and third $(2-3)$ periods, (for the bubbling bed) was found to be negligible.

Table 2 -Equations describing heat and mass transfer in mixed fluidized bed dryer

\begin{tabular}{|c|c|}
\hline Source & Equation \\
\hline Gupta, Thodos, AICHE Journal 8 (1962) $)^{19}$ & $\mathrm{Sh}=\mathrm{Re} \cdot \mathrm{Sc}^{1 / 3} \cdot\left(0.01+0.86 /\left(\mathrm{Re}^{0.58}-0.483\right)\right)$ \\
\hline Wilke, Hougen, New York, Trans. Am. Chem. Eng. $1945^{20}$ & $\mathrm{Sh}=1.82 \cdot \mathrm{Re}^{0.49} \cdot \mathrm{Sc}^{1 / 3}$ \\
\hline Wang, Chen, Chemical Engineering Science $55(2000)^{13}$ & $\mathrm{Sh}=0.989 \cdot \mathrm{Re}^{0.59} \cdot \mathrm{Sc}^{1 / 3}$ \\
\hline Reyes et al., Drying Technology $19(2001)^{21}$ & $\begin{array}{ll}\text { For } \mathrm{n}=0 & \mathrm{Nu}=0.2-1.7 \\
\text { For } \mathrm{n}=90-120 & \mathrm{Nu}=1.0-3.0\end{array}$ \\
\hline Reyes et al., Drying Technology $22(2004)^{24}$ & $\begin{array}{l}\mathrm{Nu}=0.03 \cdot \operatorname{Re}^{1.56} \\
\mathrm{Nu}=\text { const } \cdot \operatorname{Re}^{(0.5-0.8)}\end{array}$ \\
\hline $\begin{array}{l}\text { Average value from our experiments } \\
\text { (for all tested diameters of chambers were these ranges: } \\
\text { For constant: } 0.98-1.04 \text {; for exponent: } 0.58-0.62 \text { ) }\end{array}$ & $\mathrm{Sh}=1.01 \cdot \mathrm{Re}^{0.60} \cdot \mathrm{Sc}^{1 / 3}$ \\
\hline
\end{tabular}




\section{List of symbols}

$a_{s} \quad-$ Specific surface of particles

$A_{s} \quad-$ Total surface of particles

d - Diameter

$d_{s t} \quad-$ Stirrer diameter

$D_{d c h} \quad-$ Drying chamber diameter

$D_{a, b} \quad-$ Diffusivity

$g \quad-$ Acceleration of gravity

$h \quad-$ Height

$h_{0} \quad-$ Mesh size

$m$ - Mass

$n \quad-$ Amount of substance

$N_{w} \quad$ - Drying rate

$p \quad-$ Pressure

$p^{\prime \prime} \quad-$ Pressure of saturated water vapours

- Universal gas constant

- Cross-section

- Temperature

- Thermodynamic temperature

- Velocity

- Total particle volume

- Volumetric flow rate

- Absolute humidity (moisture)

- Coefficient of mass transfer

- Porosity

- Relative humidity (moisture)

- Dynamic viscosity

- Kinematic viscosity

- Density

- Drying time

\section{Criteria numbers}

$\begin{array}{ll}\mathrm{Ar} & - \text { Archimedes number, } \\ \mathrm{Nu} & - \text { Nusselt number, } \\ \mathrm{Re} & - \text { Reynolds number, } \\ \mathrm{Sc} & - \text { Schmidt number, } \\ \mathrm{Sh} & - \text { Sherwood number, }\end{array}$

\section{Subscripts and superscripts:}

$\begin{array}{ll}\text { A } & - \text { Air } \\ \text { A_B } & - \text { Air at state B } \\ \text { layer } & - \text { layer of particles } \\ \text { W } & - \text { Water (humidity, moisture) } \\ \text { SW } & - \text { Wet material } \\ \text { S } & - \text { Dry matter } \\ \text { P } & - \text { Particle }\end{array}$

$\mathrm{m}^{-1}$

$\mathrm{m}^{2}$

$\mathrm{m}$

$\mathrm{m}$

$\mathrm{m}$

$\mathrm{m}^{2} \mathrm{~s}^{-1}$

$\mathrm{m} \mathrm{s}^{-2}$

$\mathrm{m}$

$\mathrm{m}$

$\mathrm{kg}$

mol

$\mathrm{kg} \mathrm{m} \mathrm{m}^{-2} \mathrm{~s}^{-1}$

$\mathrm{Pa}$

$\mathrm{Pa}$

$\mathrm{J} \mathrm{K}^{-1} \mathrm{~mol}^{-1}$

$\mathrm{m}^{2}$

${ }^{\circ} \mathrm{C}$

$\mathrm{K}$

$\mathrm{m} \mathrm{s}^{-1}$

$\mathrm{m}^{3}$

$\mathrm{m}^{3} \mathrm{~s}^{-1}$

$\mathrm{kg}_{\mathrm{W}} \mathrm{kg}_{\mathrm{DM}}{ }^{-1}$

$\mathrm{m} \mathrm{s}^{-1}$

$-$

$\% R H(R M)$;

$\mathrm{kg}_{\mathrm{W}} \mathrm{kg}^{-1}$

$\mathrm{Pa} \mathrm{S}$

$\mathrm{m}^{2} \mathrm{~s}^{-1}$

$\mathrm{kg} \mathrm{m} \mathrm{m}^{-3}$

$\mathrm{S}$

$$
\begin{array}{ll}
\text { st } & - \text { Stirrer } \\
\mathrm{K} & - \text { Column } \\
0 & - \text { Initial point } \\
1 & - \text { Transition point between the period of the } \\
& \text { porous layer and the first period of fluid- } \\
& \text { ized-bed drying } \\
2 & - \text { Transition point between the first and the } \\
& \text { second period of fluidized-bed drying } \\
\text { A } & - \text { Zone of cold air } \\
\text { B } & - \text { Zone of heated air } \\
\text { C } & - \text { Zone of chilled wet air } \\
\text { WALL } & - \text { Wall }
\end{array}
$$

\section{References}

1. Mujumdar, A. S., Handbook of Industrial Drying, Dekker, 1995, pp 28-155.

2. Hlavačka, V., Thermal processes in technical systems of gas-solid particles (in Czech), Publishing House of Technical Literature, 1980, pp 15-62.

3. Kim, J., Han, G. Y., Effect of agitation on fluidation characteristics of fine particles in a fluidized bed, Powder Technol. 166 (2006) 113. doi: https://doi.org/10.1016/j.powtec. 2006.06.001

4. Daud, W. R. W., Fluidized bed dryers - recent advances, Adv. Powder Technol. 19 (2008) 403. doi: https://doi.org/101163/156855208X336675

5. Ying, H., Jia-Jun, W., Xue-Ping, G., Lian-Fang, F., GuoHua, $H$., Homogeneous fluidization of geldart d particles in a gas-solid fluidized bed with a frame impeller, Industrial \& Eng. Chemistry Research 51(50) 2012, 16482. doi: https://doi.org/10.1021/ie301574q

6. Ying, H., Jia-Jun, W., Xue-Ping, G., Lian-Fang, F., Guo$H u a, H$., Effect of agitation on the fluidization behavior of a gas-solid fluidized bed with a frame impeller, AIChE Journal 59 (2012) 1066. doi: https://doi.org/10.1002/aic.13893

7. Williams, P. A., Hudson, M. J., Recent Developments in Ion Exchangers, Ion Exchangers in the Nuclear Industry, Springer, Netherlands, 1990, pp 13-39. doi: https://doi.org/10.1007/978-94-009-0777-5

8. Jelinek, L., Desalination and separation methods in water treatment (in Czech), Prague Institute of Chemical Technology, 2009, pp 15-24.

9. T. o. T. D. C. C. (. o. a. a. c. o. Dow, DoweX marathon A, 26112010 , [Online].

doi: http://www.dowwaterandprocess.com/products/ix/dx mar_a.htm. [Approach obtained 22.05.2011].

10. Mega.cz, RALEX heterogenous ionex membranes (in Czech). QARTIN s.r.o., [Online].

doi: http://www.mega.cz/heterogenni-iontomenicove-membrany-ralex.html. [Approach obtained 20.11.2012].

11. Chyský, J., Moist air (in Czech). Publishing House of the Czech Technical University in Prague, 1977, 15-53.

12. Novák, V., Rieger, F., Hydraulic processes (in Czech), Publishing House of the Czech Technical University in Prague, 2005, 256-260.

13. Wang, H.,Chen, G., Heat and mass transfer in batch fluidized-bed drying of porous particles, Chemical Engineering Science 59 (2000) 1857. doi: https://doi.org/10.1016/S0009-2509(99)00446-7 
14. Šesták, J., Bukovský, J., Houška, M., Thermal Processes: Transport and thermodynamic data (in Czech), Publishing House of the Czech Technical University in Prague, 1993, pp 50-56.

15. Touloukian, S. H., Thermophysical properties of matter, sv. 11. IFI/Plenum Press, 1975.

16. Wen, $C$., $Y u, Y$., A generalized method for predicting the minimum fluidization velocity, AIChE Journal 12 (1966) 610.

doi: https://doi.org/10.1002/aic.690120343

17. Gupta, D., Diffusion process in advanced technological materials, Norwich: Andrew, 2005, pp 14-30. doi: https://doi.org/10.1007/978-3-540-27470-4

18. Rieger, F., Novák, V., Jirout, T., Hydrodynamic processes (in Czech), Publishing House of the Czech Technical University in Prague, 2005, pp 251-260.

19. Gupta, A. S., Thodos, G., Mass and heat transfer in the flow of fluids through fixed and fluidized beds of spherical particle, Houston: AIChE Journal 8 (1962) 608. doi: https://doi.org/10.1002/aic.690080509

20. Wilke, C. R., Hougen, O. A., Mass transfer of gas mixture, New York: Trans. Am. Int. Chem. Eng. 1945.

21. Reyes, A., Diaz, G., Marquardt, F. H., Analysis of mecanically agitated fluid-particle contact dryers, Drying Technology 19 (2001) 2235.
22. Reyes, A., Alvarez, P. I., Marquardt, F. H., Drying of carrots in a fluidized bed, I. Effect of drying conditions and modelling, Drying Technology 20 (2002) 1463.

23. Reyes, A., Eckholt, M., Alvarez, P. I., Drying and heat transfer characteristics for a novel fluidized bed dryer, Drying Technology 22 (2004) 1869.

24. Reyes, A., Herrera, N., Vega, R., Drying suspensions in a pulsed fluidized bed of inert particles, Drying Technology 26 (2008) 122.

25. Adamiec, J., Drying of waste sludges in a fluidized bed dryer with a mixer, Drying Technology 20 (2002) 839.

26. Bait, R. G., Pawar, S. B., Banerjee, A. N., Mujumdar, A. S., Thorat, $B . N$., Mechanically agitated fluidized bed drying of cohesive particles at low air velocity, Drying Technology 29 (2011) 808.

27. Puspasari, I., Talib, M. Z. M., Daud, W. R. W., Tasirin, S. $M$., Drying kinetics of palm oil frond particles in an agitated fluidized bed dryer, Drying Technology 30 (2012) 619.

28. Chongdian, S., Wu, J., Wang, Y., Zhang, Y., Shang, X., Drying of low rank coals: A review of fluidized bed technologies, Drying Technology 33 (2015) 277.

29. Kim, J., Han, G. Y., Effect of agitation on fluidization characteristics of fine particles in a fluidized bed, Powder Technology 166 (2006) 113. 